http://jmscr.igmpublication.org/home/

ISSN (e)-2347-176x ISSN (p) 2455-0450

crossref DOI: https://dx.doi.org/10.18535/jmscr/v8i7.86

Journal Of Medical Science And Clinical Research

\title{
A Prospective Study on Clinical Evaluation and Management of Diabetic Wounds according to Wagners Classification in Tertiary Care Hospital
}

\author{
Authors \\ Dr Narayana Swamy $\mathbf{T}^{\mathbf{1}}$, Dr Chandra Vamsi Krishna $\mathbf{M}^{\mathbf{2}}$ \\ ${ }^{1}$ Professor and Unit Chief, Department of Surgery, KIMS Hospital, Bengaluru-560004 \\ ${ }^{2}$ Post Graduate, Department of Surgery, KIMS Hospital, Bengaluru -560004 \\ Corresponding Author \\ Dr Chandra Vamsi Krishna M \\ Post Graduate in Department of General Surgery, KIMS Hospital ,VV Puram, KR Road, \\ Bengaluru 560004, India
}

\begin{abstract}
Background: Most important complication in diabetic patients are Diabetic foot which represents a major medical, social and economic problem worldwide that significantly influence the diabetic patients quality of life. Several classification systems for diabetic foot ulcers have been proposed. The present study was intended to assess the role of Wagners wound classification in predicting the outcome of diabetic foot ulcer and also know the grade of Wagner's classification to which majority of diabetic foot ulcer patients.
\end{abstract}

Methods: This present study was carried out in the Department of General Surgery, KIMS Hospital, Bengaluru. A total of 100 patients with diabetic foot ulcer who presented during the study period were included. The diabetic foot ulcers were graded according to the Wagner's classification.

Results: Age group of 41-60 years and above 61 years showing the risk of diabetic foot ulcers in this study. In gender, males are more affected (72\%) than females (38\%) and most common age group fall in 41-60 years for both males and females. Neuropathy may influence the diabetic foot ulcers irrespective of gender. Nature of lesions showed that Deep thickness ulcers were higher in this study $36 \%$ followed by others. Wagner's classification showed Grade II is more prevalent in this study.

Conclusion: Glycaemic control and proper foot care, education about diabetic foot are key factors for better out come and quality of life.

Keywords: Diabetic Foot Ulcers, Wagner's Classification.

\section{Introduction}

Diabetes is a common disease affecting about $2.4 \%$ in rural and $4 \%-11.6 \%$ in urban dwellers in India ${ }^{1}$. India has highest prevalence of diabetes in world and accounts for almost $1 / 6^{\text {th }}$ the diabetic patients. Approximately $10 \%-25 \%$ of all diabetics will develop some foot complications during the course of illness from simple calluses to major abscesses and osteomyelitis. Several classifications exist for grading ulceration and 
their management; however Wagner's classification is the simplest, best known for evaluation and management of diabetic foot ulceration $^{2}$. Relative Risk of leg amputation is 40 times higher among person with diabetes than with those not diabetic. Moreover, up to $50 \%$ of diabetic amputees will undergo a second leg amputation within 5 years of initial amputation. Complications involving the foot cause significant pain and suffering, loss of productive time, hospitalization, heavy expenses to the patient, community and nation as well. To add to above vascular insufficiency and neuropathy accompanying the diabetic foot most often necessitate amputation of the $\operatorname{limb}^{3}$. In India habits like walking barefooted, lack of knowledge regarding diabetic foot, hot climate leading to increased perspiration, poor hygiene, poor sanitation, diet poor in proteins, general poverty, lack of basic medical infrastructure, etc have worsened the problem. Lack of interest from medical and surgical faculty due to required hard work for this field has added to the problem statement. The management of diabetic foot is focused primarily on avoiding amputation of lower extremities. Hence early recognition and proper therapy of diabetic foot lesion may save diabetic foot and $\operatorname{leg}^{1}$. The amount of interest in the diabetic foot has increased tremendously over the past ten years. There continues to be great interest in the treatment and prevention of diabetic foot. Wagner's classification helps in correlating appropriate treatment to proper grade of lesion with better outcome ${ }^{4}$. Lesser grade lesion responds well to conservative treatment with antibiotics and debridement while those with higher lesion require some kind of amputation Standard treatment of diabetic foot according to Wagner classification

\begin{tabular}{|l|c|c|}
\hline GRADE 0 & Foot at Risk & Prevention \\
\hline GRADE 1 & $\begin{array}{c}\text { Localized, } \\
\text { superficial ulcer }\end{array}$ & $\begin{array}{c}\text { Antibiotics \& glycemic } \\
\text { control }\end{array}$ \\
\hline GRADE 2 & $\begin{array}{c}\text { Dep Ulcer to bone, } \\
\text { ligament, or joint }\end{array}$ & $\begin{array}{c}\text { Debridement, } \\
\text { Antibiotics and } \\
\text { glycemic control }\end{array}$ \\
\hline GRADE 3 & $\begin{array}{c}\text { Deep abscess, } \\
\text { osteomyelitis } \\
\text { Gangrene of toes, } \\
\text { forefoot }\end{array}$ & $\begin{array}{c}\text { Debridement, some } \\
\text { form of amputation } \\
\text { Wide debridement and } \\
\text { amputation }\end{array}$ \\
\hline GRADE 4 & $\begin{array}{c}\text { Gangren of entire } \\
\text { foot }\end{array}$ & Below knee amputation \\
\hline
\end{tabular}

\section{Materials and Methods}

This prospective study was conducted by General surgery department, KIMS Hospital, Bengaluru between December 2018 to December 2019. All patients were enrolled after taking written consent form. In the present Prospective hospital-based study, a total of 100 cases diagnosed with diabetic foot were selected to inpatients of Department of general surgery, KIMS hospital, Bengaluru .Institutional ethics committee permission was taken. Data was collected about Demographic factors, ethnicity, socioeconomic status, smoking habits, tobacco chewing, alcohol intake history and occupational exposures. Clinical parameters include foot ulcers onset, duration and progression of the disease. Wagner's classification for diabetic foot was used for evaluation of ulcers. Neurological assessment was performed including light touch, pinprick, position sense and vibration sense. Vascular assessment was done by examining capillary refill and distal pulses of the foot which included dorsalis pedis, posterior tibial, anterior tibial, popliteal and femoral arteries. 


\section{Results}

Descriptive statistics like mean and percentages were used to interpret the results

\section{Table 1}

\begin{tabular}{|l|c|}
\hline VARIABLES & NO of patients (n =100) \\
\hline Age (in years) & $12(12 \%)$ \\
$21-40$ & $50(50 \%)$ \\
$41-60$ & $38(38 \%)$ \\
$>61$ & \\
\hline Gender & $72(72 \%)$ \\
Males & $28(28 \%)$ \\
Females & \\
\hline Neuropathy & $62(62 \%)$ \\
Neuropathy Present & $38(38 \%)$ \\
Neuropathy Absent & \\
\hline Nature of Lesion & $17(17 \%)$ \\
Superficial ulcers & $36(36 \%)$ \\
Deep thickness ulcers & $21(21 \%)$ \\
Cellulitis & $10(10 \%)$ \\
Abscess & $15(15 \%)$ \\
Gangrene & $01(01 \%)$ \\
Necrotizing fasciitis & \\
\hline Distribution according to Wagner's & \\
classification Wagner's Grade: & $00(0 \%)$ \\
Grade 0 & $17(17 \%)$ \\
Grade I & $36(36 \%)$ \\
Grade II & $27(27 \%)$ \\
Grade III & $14(14 \%)$ \\
Grade IV & $06(06 \%)$ \\
Grade V & \\
\hline
\end{tabular}

Table 2: Treatment modalities in the present study

\begin{tabular}{|l|l|}
\hline Conservative & 16 \\
\hline Debridement & 21 \\
\hline Disarticulation & 22 \\
\hline Fasciotomy & 12 \\
\hline Debridment + SSG & 14 \\
\hline Debridement + fasciotomy & 03 \\
\hline I and D & 06 \\
\hline Below knee amputation & 05 \\
\hline Above knee amputation & 01 \\
\hline
\end{tabular}

Table 1 shows the clinico-demographic factors from the patients of present study. The data shown that incidences of diabetic foot is more in age group of 41-60 years age groups and above 61 years showing the risk of age factor. In gender, males are more affected (72\%) than females $(38 \%)$ and most common age group fall in 41-60 years for both male and females. Irrespective of gender incidence of neuropathy condition was higher when compared with non neuropathy patients. Nature of lesions showed that Deep thickness ulcers were higher in this study $36 \%$ followed by cellulitis, Gangrene, Abscess, superficial ulcers, and necrotizing fasciitis. Patients were stratified according to Wagner classification, showed that Grade II (36\%) frequency is higher in our study followed by grade III, grade I, grade IV and grade V. Of the 100 diabetic patients the most common procedure followed was Disarticulation (22\%) and Debridement (21\%). For other patients conservative treatment $(16 \%)$ and procedures like Debridement +SSG (14\%), Debridement + fasciotomy (3\%), Fasciotomy (12\%), I and D $(6 \%)$, amputations $(6 \%)$ was performed (TABLE 2). 


\section{Discussion}

For years, Wagner's classification for diabetic foot ulcers is using for the assessment and management of the diabetic foot due to it is a simplest, best known method for evaluation and management of diabetic foot ulcers. Age groups of the present study shown that age range of 40-60 years and above are in higher risk group. The results are in accordance with Ahmad et al 201316. The results of the present study are in similar with Anil gupta et al., 2016 and Ali Sm et al., 2001 where the males are predominantly have risk of diabetic foot ulcers when compared with females (table 1). Regarding to peripheral neuropathy, the present study showed a higher number of cases than absence of neuropathy may be associated with diabetic complication among the patients group. After seeing the results, Neuropathy (62\%) may be an important risk factor for diabetic foot infections. According to the Wagner classification $36 \%$ patients had grade II disease and occupied highest frequency in this study. In the present study after assessing patients with diabetic foot ulcers by Wagner's classification, the most important initial finding need to asses in the patients is whether patient had a neuropathic or not? If the patient is known to be neuropathic, pressure relief was the mainstay of treatment. We found poor vascular status in few cases, those cases were referred to vascular surgeon for further management.

\section{Conclusion}

Foot ulceration in diabetic patients is resource consuming, disabling morbidity, and often the first step towards lower extremity amputation. Prevention is the best treatment. Wagner's classification helps in correlating appropriate treatment to proper grade of lesion with better outcome. Lesser grade lesions respond well to conservative treatment with antibiotics and debridement while those with higher lesions require some kind of amputation. Effective glycaemic control and education are of key importance for decreasing diabetic foot disease.
With early presentation and hospital admission, aggressive medical and surgical treatment according to the grade of the disease can improve outcome and reduce the morbidity and mortality due to diabetes.

\section{References}

1. Connor $\mathrm{H}$ Some Historical Aspects of Diabetic Foot Disease. Diabetes Metab Res Rev. 2008; 24(1):S7-S13.

2. Pryce TD: A Case of Perforating Ulcers of Both Feet Associated with Diabetes and Ataxic symptoms. Lancet.1887; 11:11-2.

3. Park SY, et al. Effects of foot complications in patients with Type 2 diabetes mellitus on public healthcare: An analysis based on the Korea National Diabetes Program Cohort. J Diabetes Complications.2016; 16:30253-7.

4. Joshi SR, Parikh RM. India - Diabetes Capital of the World: Now Heading Towards Hypertension. J Assoc Physicians India.2007; 55:323-4.

5. International Diabetes Federation, Diabetes Atlas, 5th Edition, 2012

6. Fard AS, Esmaelzadeh M, Larijani, B. "Assessment and treatment of diabetic foot ulcer," International Journal of Clinical Practice, 2007; 61(1):1931-1938.

7. Ahmad W, Khan IA, Ghaffar S, Al-Swailmi FK, Khan I. Risk factors for diabetic foot ulcer. J Ayub Med Coll Abbottabad, 2013; 25(7):16-18.

8. Anil G, Haq M, Singh M. Management Option in Diabetic Foot According to Wagners Classification: An Observational Study. JK SCIENCE, 2016; 18, 35-38.

9. Ali SM, Basit A, Sheikh T, Mumtaz S, Hydrie MZ. Diabetic foot ulcer--a prospective study. J Pak Med Assoc, 2001; 51(5):78-81.

10. Viswanathan V, Thomas N, Tandon N, Asirvatham A, rajasekhar s, Ramachandran a, et al. profile of diabetic foot complications and its associated complications- -a multicentric study from India. J Assoc Physicians India, 2005;53(4):933-936. 